Article

\title{
Economic and Environmental Study of Wineries Powered by Grid-Connected Photovoltaic Systems in Spain
}

\author{
Daniel Gómez-Lorente ${ }^{1, *}$, Ovidio Rabaza ${ }^{1}$, Fernando Aznar-Dols ${ }^{1}$ \\ and María José Mercado-Vargas 1 \\ Department of Civil Engineering, University of Granada, 18010 Granada, Spain; ovidio@ugr.es (O.R.); \\ faznar@ugr.es (F.A.-D.); mjmercado@ugr.es (M.J.M.-V.) \\ * Correspondence: dglorente@ugr.es; Tel.: +34-958-249-517 \\ Academic Editor: Thomas E. Amidon \\ Received: 1 October 2016; Accepted: 7 February 2017; Published: 14 February 2017
}

\begin{abstract}
This research developed a system that can make factories more independent from the grid. The system enhances efficiency since factory operation is powered by the renewable energy generated during the production process. Winemaking is a key sector that can profit from such a system because wineries can recycle much of the waste from the raw materials employed in wine production. Moreover, the solar energy collected at winemaking facilities can also be used to reduce electricity consumption and thus increase energy efficiency. This study investigated the feasibility of using renewable energy sources, such as solar energy, in wineries in Spain, given the quantity of renewable energy produced in the country. For this purpose, cost-effectiveness, power generation, $\mathrm{CO}_{2}$ emissions and the renewable energy fraction were taken into account. The assumption was that the photovoltaic system was grid-connected. Research results showed a reduction in electrical power costs ranging from $4 \%$ to $36 \%$. This reduction was accompanied by an increase in the use of renewable energy of up to $57 \%$. The results obtained are based on self-consumption or net metering policy as well as the production capacity of the winery.
\end{abstract}

Keywords: wineries; sustainability; net metering; solar energy; self-consumption

\section{Introduction}

The world economy has the urgent need to become independent of fossil fuel energy resources because of their limited availability and the possibility of their eventual depletion. These problems have arisen because of global political constraints and the lack of suitable infrastructure in many countries. Therefore, nations of the world should envisage and implement strategies to replace fossil fuel with renewable energy resources. Climate change, the Kyoto Protocol, and the need to reduce energy costs are obliging industries to rapidly acquire knowledge of energy options in key sectors [1], such as the agri-food sector. For example, photovoltaic $(P V)$ energy is one of the renewable energy sources that is widely used in the agricultural sector for various activities [2,3], such as water pumping systems for irrigation, or electricity generation [4-6]. Nevertheless, to date, it has not been widely used in wine production.

The winemaking sector is extremely important, not only for its economic value but also for the number of jobs created and its crucial role in the conservation of the environment. According to the International Organization of Vine and Wine (OIV in Spanish), in 2009, Europe was the continent with the largest percentage of total vineyard area: $44 \%$ compared to $36.4 \%$ in Asia; $20.7 \%$ in the Americas; $6.0 \%$ in Africa; and 2.8\% in Oceania. In 2011, global wine production totaled 265.8 million hectoliters compared to a consumption of 241.9 million. In Spain, the wine industry comprises 4300 factories, 
which make up $14.0 \%$ of the Spanish food industry. In fact, its net value is approximately 5500 million euros, which is $1.0 \%$ of the Spanish GDP [7].

Incident solar irradiance on buildings or areas where wineries are located is an important renewable energy source that can be used instead of fossil fuels. This significantly reduces costs as well as $\mathrm{CO}_{2}$ emissions. According to data published by agri-food cooperatives and the Spanish Ministry of the Environment, Marine and Rural Affairs, over 3100 Spanish wineries have an average annual electricity consumption of $164,203 \mathrm{kWh}$ with an average price of $0.124 € / \mathrm{kWh}$. This comes to an annual energy cost of $20,345 €$ per winery. This cost could be greatly reduced if the wineries used the system presented in this paper.

Competition in the wine sector is swiftly increasing. Precisely for this reason, any measure that improves energy efficiency and therefore reduces wine production costs will increase profits and will make production less dependent on energy price fluctuations. One of the main problems in the wine industry is that electricity consumption is non-homogeneous, since it occurs mainly during the harvest and wine production season (i.e., August to November). During the rest of the year, energy consumption is very low and mostly stems from storage, packaging, and auxiliary activities such as the lighting and air-conditioning in office installations. This uneven level of energy consumption during the year makes costs soar because wine factories are obliged to hire the power corresponding to the months with a high energy consumption.

Our research showed that the use of renewable energies was the best solution to reduce energy costs as well as $\mathrm{CO}_{2}$ emissions into the atmosphere. Nevertheless, not all renewable sources are suitable for this purpose. Given the climate conditions of southern Europe, our study specifically focused on solar energy.

This research was based on data from the energy audits of eight wineries, as performed by five federations and territorial unions of Spanish agri-food cooperatives (FUTs) [8], where the actual energy consumption data and wine production figures were analyzed. Based on these data, the wineries were classified in three groups (see Table 1).

Table 1. Wine industry data, according to winery size [8].

\begin{tabular}{cccccc}
\hline $\begin{array}{c}\text { Classification of } \\
\text { Wineries }\end{array}$ & $\begin{array}{c}\text { Total Production } \\
\text { Ranges (Hl) }\end{array}$ & $\begin{array}{c}\text { Average } \\
\text { Production (Hl) }\end{array}$ & $\begin{array}{c}\text { Electricity } \\
\text { Consumption } \\
\mathbf{( k W h )}\end{array}$ & $\begin{array}{c}\text { Electricity } \\
\text { Consumption/Total } \\
\text { Production } \\
\text { (kWh/Hl) }\end{array}$ & $\begin{array}{c}\text { Electricity } \\
\text { Cost/Total } \\
\text { Production (E/hl) }\end{array}$ \\
\hline Small & $<25,000$ & 9696 & 158,148 & 16.31 & 2.31 \\
Medium & {$[25,000,50,000]$} & 28,430 & 285,442 & 10.04 & 1.26 \\
Large & $>50,000$ & 119,710 & 450,109 & 3.76 & 0.43 \\
\hline
\end{tabular}

The objective of this research was to verify the feasibility of grid-connected photovoltaic systems in wineries and to foment their installation in other countries where wine is produced. This is in consonance with EU policy that envisages a substantial increase in the use of renewable energy sources. The goal was to determine whether the energy required for the operation of small, medium, and large wineries in Spain could be obtained from grid-connected $P V$ systems with a high level of cost-effectiveness. We also wished to contribute to a better understanding of renewable energy use in commercial activities such as the agri-food industry. For this purpose, incident solar irradiance was analyzed at all of the wineries in Spain. The conclusion was that solar radiance levels were similar throughout Spain and that differences between regions were negligible.

\section{Wineries Energy Consumption}

Wineries consume both electrical and thermal energy. Electrical energy is used to power the equipment of the winery, and thermal energy is used for heating, domestic hot water, washing bottles and barrels, and also for operating forklifts. In most of the wineries, water is heated in a boiler that uses 
fossil fuel, except for some that use a biomass boiler. Table 1 shows the average electricity consumption of each winery in relation to its wine production.

Not surprisingly, energy consumption is proportional to wine production. Accordingly, the data pertaining to the average annual wine production and electricity consumption [8] can be used to obtain the electricity consumption per volume unit of wine for each of the three types of winery.

As can be observed, larger wineries have lower energy consumption values than smaller ones, are thus more efficient. Since larger wineries are usually of more recent construction, their technology tends to be more modern. In contrast, the absolute operating costs of small and medium-size wineries are very similar. Small wineries have the highest cost-production ratio because they have the lowest production of wine.

The energy consumption and costs in Table 1 were used to ascertain the size of the optimal renewable energy system that would decrease these costs as much as possible for each type of winery. The model developed in our research is extremely useful because it can improve the sustainability of this agri-food sector.

\section{The Influence of Temporariness on Energy Consumption}

The energy consumption of the winemaking sector depends on the time of the year. There are times when consumption is extremely high whereas at others, it is quite low. Figure 1 shows the seasonal nature of the energy consumption in wineries, based on data for the one-year time period audited by the FUTs.

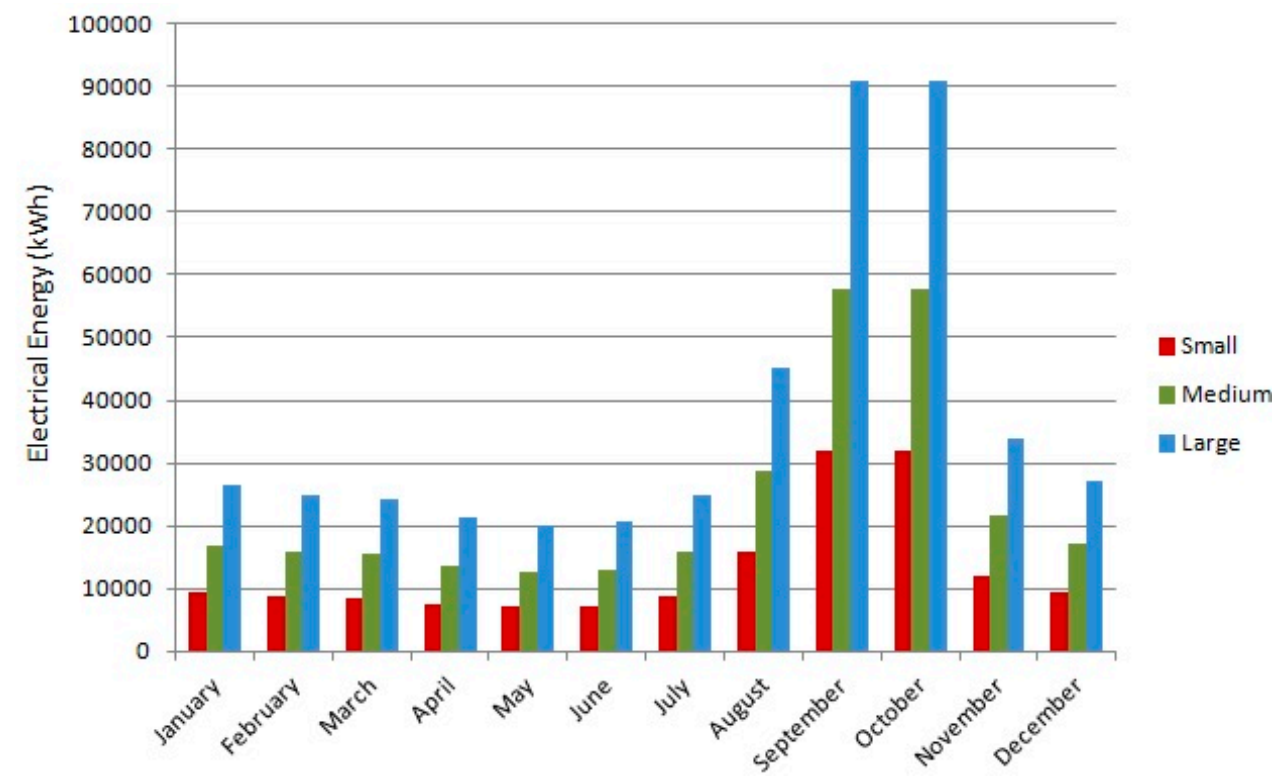

Figure 1. Average electrical energy consumption of the wineries, depending on their size.

\section{Renewable Energy Resource}

Spain has an area of approximately $504,645 \mathrm{~km}^{2}$ and is located in the warm-temperate region of southwest Europe at a latitude of $40^{\circ} 25^{\prime} \mathrm{N}$ and a longitude of $3^{\circ} 45^{\prime} \mathrm{W}$, as shown in Figure 2. The country has three major climate zones. The Mediterranean climate, which dominates the Iberian Peninsula, is characterized by warm dry summers. The semi-arid climate zone in the southeastern region of the country differs from the Mediterranean climate zone because the dry season extends beyond the summer. Finally, northern Spain has an oceanic climate, where the ocean influences summer and winter temperatures, and there is no seasonal drought [9]. The average temperature in Spain throughout the year is $14-17^{\circ} \mathrm{C}$, The coldest month is January with an average temperature of $4-6^{\circ} \mathrm{C}$, and the hottest months are July and August with an average temperature of $24-26^{\circ} \mathrm{C}$. 


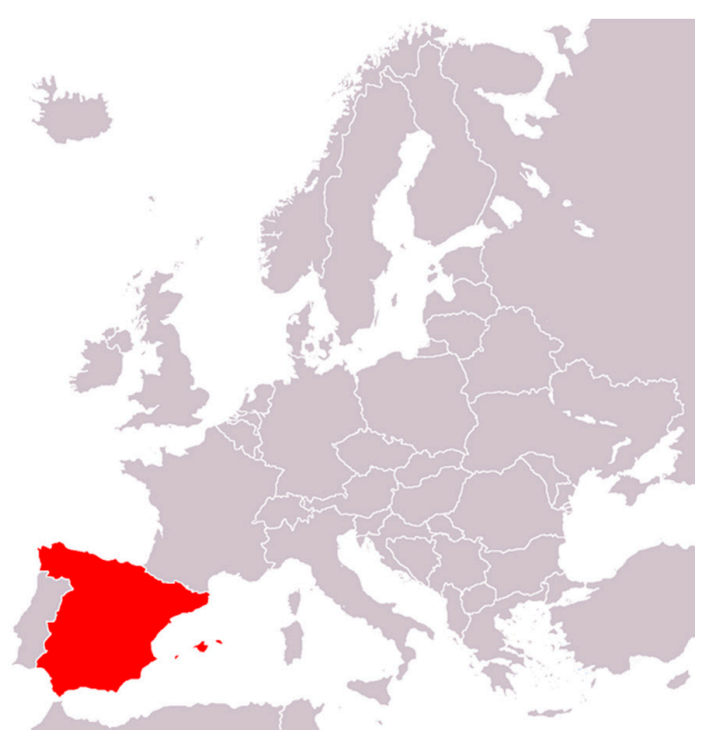

Figure 2. Geographic location of Spain [10].

\section{Solar Resources}

The U.S. National Renewable Energy Laboratory (NREL, Boulder, CO, USA) provided the monthly solar radiation data used in this study. Figure 3 shows the daily global horizontal radiation and clearness index during the year. The lowest global horizontal solar radiation is $1.7 \mathrm{kWh} / \mathrm{m}^{2} /$ day whereas the highest one is $7.2 \mathrm{kWh} / \mathrm{m}^{2} /$ day, with an annual average value of $4.4 \mathrm{kWh} / \mathrm{m}^{2} /$ day. The months with the highest solar radiation are those between April and September. Hybrid Optimization of Multiple Energy Resources (HOMER), the software application used in this study automatically calculated the clearness index, based on daily radiation data [11].

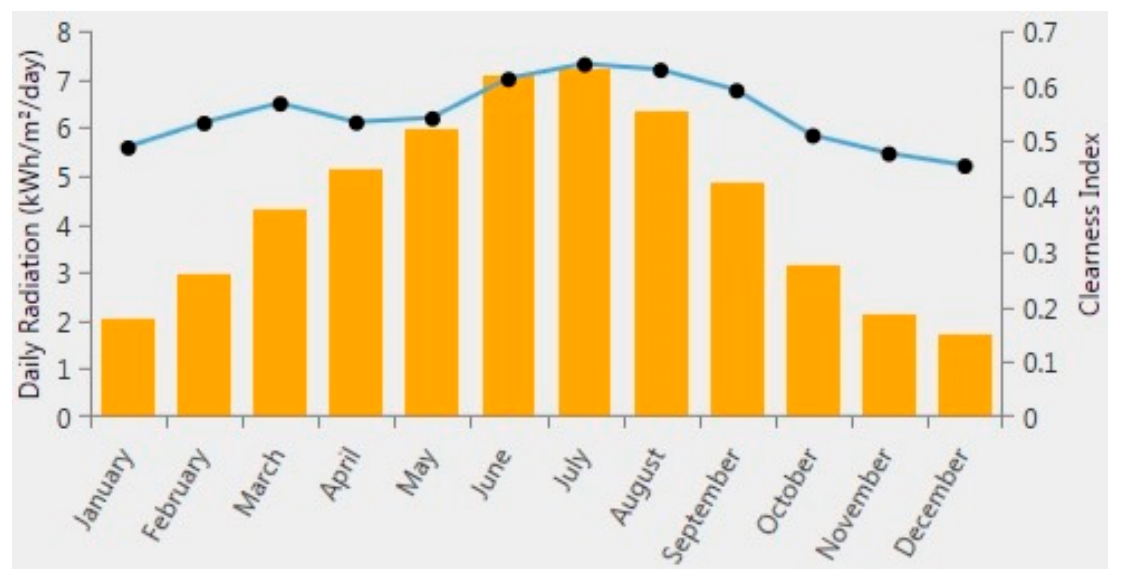

Figure 3. Daily global horizontal solar radiation and clearness index in Spain implemented in the HOMER software application.

\section{Materials and Methods}

To design the system and study its feasibility, we used HOMER, a computer application, developed by NREL. This software can be used to design electricity generation systems and even to compare them with other types of system. HOMER can also simulate the performance of electrical energy systems with renewable energy sources. The application takes into account the useful life of the system to calculate its optimal design and dimensioning, based on environmental, technical, and economic parameters. 
Economic and technical evaluation criteria were used to assess the feasibility of wineries with a grid-connected $P V$ system. After first assessing the technical viability of the system and whether it was able to meet the load demand, HOMER calculated the economic parameters. The major issues considered in the technical feasibility study were energy load consumption and the space required to position the renewable source. All costs during the system's useful life were evaluated, including the initial set-up costs (IC), component replacements within the system's useful life, maintenance and operating costs (M\&O), and purchasing power costs (PPC) from the grid. The lifetime cycle cost of the system was represented by the net present cost (NPC) and calculated with the following equation [12]:

$$
N P C=\frac{T A C}{C R F(i, N)}
$$

where $T A C$ is the total annualized cost $(€ /$ year) and $C R F$ is the capital recovery factor given by:

$$
\operatorname{CRF}(i, N)=\frac{i(i+1)^{N}}{(i+1)^{N}-1}
$$

where $N$ is the number of years; and $I$ is the annual real interest rate (\%). The cost of energy (COE) produced by the system was also used as a techno-economic evaluation criterion. The COE represents the unit cost of the energy produced by the system and was calculated by dividing the total annualized cost by the annually produced energy as follows:

$$
C O E=\frac{T A C}{E_{P V}}
$$

\subsection{System Model}

Figure 4 shows the proposed system.

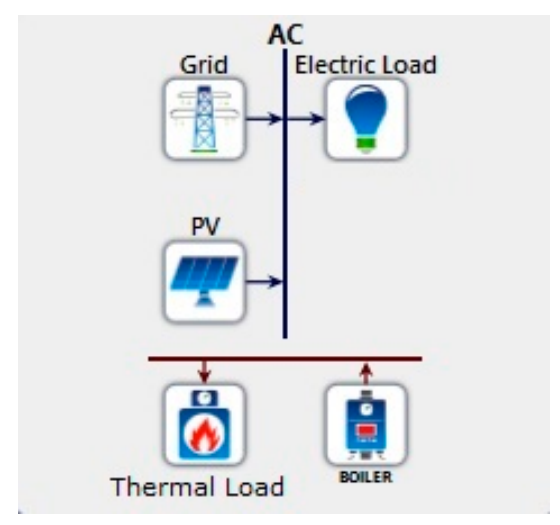

Figure 4. Basic setting of loads and sources in HOMER.

As can be observed in Figure 4, the system is composed of a photovoltaic installation and a biomass boiler, which provides the winery with part of the power necessary for its smooth operation. The photovoltaic installation is directly connected to the grid. As such, it provides electrical energy, which is priced with a bi-directional meter. The boiler uses biomass as fuel to heat water. Despite the fact that wineries consume a great deal of water, most of it is cold water, which is mainly used to clean hoppers, destemmers, deposits, pumps, and pipes. Hot water is mostly consumed in the bathrooms and showers of the offices, laboratories, and changing rooms. The electricity to heat the water for these services is negligible in comparison to the total amount of electrical energy consumed in the winery. For this reason, even though the biomass boiler was included as part of the system, it was not considered in the calculations. 
The optimal solution for large, medium, and small wineries were determined with HOMER, based on the electricity consumption data in Table 1. As previously mentioned, most electricity in wineries is consumed from August to November. During the other months, electricity is only needed for office facilities (lighting, air-conditioning, etc.), and power consumption is thus quite low. Figure 1 shows the monthly electricity load profile for the three types of winery.

\subsection{Economics Interest Rate Less the Inflation Rate}

The interest rate was $0.4 \%$, which is equal to the nominal interest rate minus the inflation rate. The average useful life of the system was fixed at 25 years. However, the interest rate can vary, depending on the economic conditions of the area where the project was evaluated. According to the Central European Bank, the Eurozone has a nominal interest rate of $0.2 \%$ and an inflation rate of $-0.2 \%$ (December 2014) [13].

\subsection{PV Module}

The power provided by a photovoltaic system mainly depends on the available solar radiation. In our study, the $P V$ installation provided $A C$ power by using electrical inverters connected to the photovoltaic modules. The photovoltaic power was obtained with the following formula:

$$
P_{P V}=W_{P V} f_{P V} \frac{G_{T}}{G_{S}}
$$

where $W_{P V}$ is the peak power output of the $P V$ module $(\mathrm{kW}) ; f_{P V}$ is the $P V$ de-rating factor $(\%) ; G_{T}$ is the solar radiation incident on the $P V$ module in the current hour $\left(\mathrm{kW} / \mathrm{m}^{2}\right)$; and $G_{S}$ is the incident radiation under standard test conditions $\left(1 \mathrm{~kW} / \mathrm{m}^{2}\right)$.

Since an increase in temperature causes a drop in the efficiency of the module, temperature variation was also considered. The following formula was used to calculate the effect of temperature on the power output of the $P V$ module:

$$
P_{P V}=W_{P V} f_{P V} \frac{G_{T}}{G_{S}}\left[1+k_{P}\left(T_{C}-T_{S T C}\right)\right]
$$

where $k_{P}$ is the temperature power coefficient $\left(\% /{ }^{\circ} \mathrm{C}\right) ; T_{C}$ is the $P V$ module temperature in the current hour $\left({ }^{\circ} \mathrm{C}\right)$; and $T_{S T C}$ is the $P V$ module temperature under standard test conditions $\left(25^{\circ} \mathrm{C}\right)$.

This study focused on photovoltaic systems of up to $100 \mathrm{~kW}$. The costs of installation, operation, and maintenance were obtained from the NREL (NREL 2015). Table 2 shows the $P V$ installation data that were entered into HOMER in order to assess the economic and technical viability of the system.

Table 2. $P V$ system cost and characteristics.

\begin{tabular}{cc}
\hline Description & Cost/Information \\
\hline Capital cost & $3552 € / \mathrm{kW}_{\mathrm{AC}}$ \\
Replacement cost & $2330 € / \mathrm{kW}_{\mathrm{AC}}$ \\
O\&M & $17.7 € /$ year \\
Life time & 25 years \\
$P V$ tracking & No tracking \\
Derating factor & $80 \%$ \\
Slope (degrees) & 37.17 \\
Ground reflectance & $20 \%$ \\
\hline
\end{tabular}

An 80\% reduction factor was selected, which represents the difference between the performance of the photovoltaic panels in ideal conditions and their real performance, which is somewhat lower because of temperature increases and occasional shading. Although this reduction factor is usually $90 \%$, a value of $80 \%$ is generally chosen in hot countries because of the higher temperatures that 
lower the efficiency of the photovoltaic cells. In our study, the shading of the photovoltaic panels [14] was negligible because wineries are generally located in isolated rural area far away from other buildings. Consequently, the only shading would be from clouds. In Homer, this type of shading is only represented in the data pertaining to the global radiation of the location, which is composed of the direct and diffuse radiation. The replacement cost of a $P V$ system was calculated, based on a useful life of 25 years and the estimated pricing trends for that time period [15].

\subsection{Grid Input}

The energy rate depends on the time of year and the time of day when consumption occurs. Figure 5 thus shows the three time periods for electricity consumption in Spain: peak, off-peak, and shoulder. Each period is priced differently. Furthermore, electricity companies do not have the same price agreement with the three types of winery because the final cost depends on the total power consumption of the winery. Accordingly, the electrical power price depended on the size of the winery and was averaged for each time period. Tables 3 and 4 show the grid power price and demand price for each type of winery and for each time period in 2014.

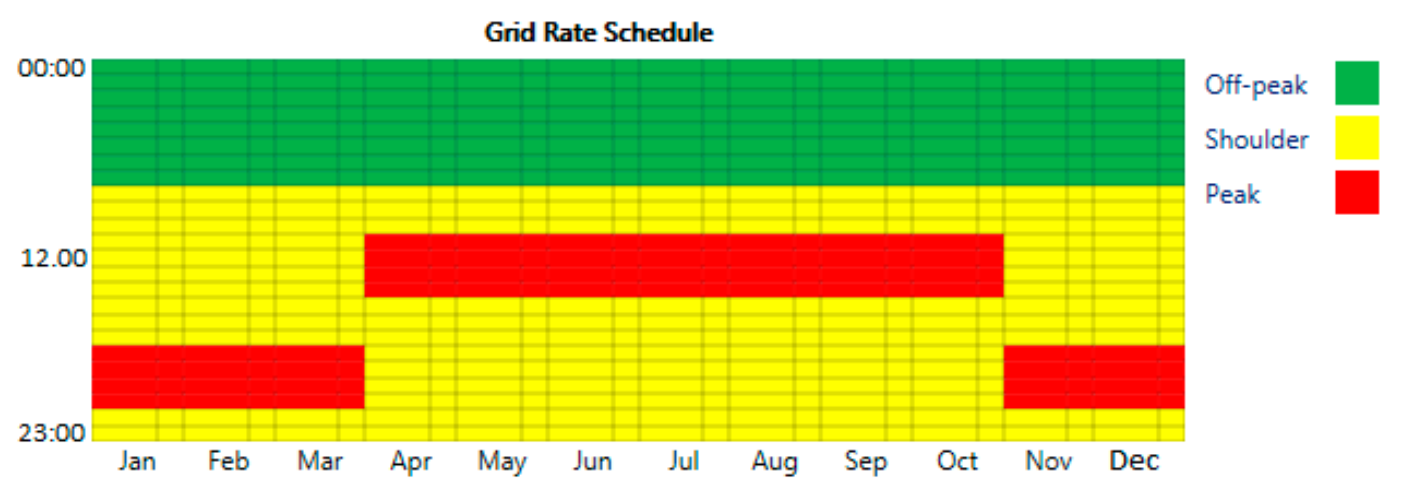

Figure 5. Rate schedule implemented in HOMER.

Table 3. Grid power price.

\begin{tabular}{cccc}
\hline $\boldsymbol{\epsilon} / \mathbf{k W h}$ & Off-Peak Rate & Shoulder Rate & Peak Rate \\
\hline Small & 0.0828 & 0.1248 & 0.1324 \\
Medium & 0.0724 & 0.1092 & 0.1159 \\
Large & 0.0690 & 0.0990 & 0.1045 \\
\hline
\end{tabular}

Table 4. Demand price.

\begin{tabular}{cccc}
\hline $\boldsymbol{\epsilon} / \mathbf{k W}$ /Month & Off-Peak Rate & Shoulder Rate & Peak Rate \\
\hline Small & 0.8067 & 3.6114 & 5.8562 \\
Medium & 0.7058 & 3.1586 & 5.1238 \\
Large & 0.5756 & 2.5763 & 4.1776 \\
\hline
\end{tabular}

The electricity obtained from solar radiation and fed to the grid, has a fixed price of $0.05 € / \mathrm{kWh}$ which is paid by the electricity company.

\subsection{Equivalent $\mathrm{CO}_{2}$ Assessment}

Although it is true the $P V$ system does not produce $\mathrm{CO}_{2}$ emissions, conventional energy sources are used to manufacture $P V$ modules as well as other components of the $P V$ system (inverters, aluminum frames, etc.). Table 5 thus shows the $\mathrm{CO}_{2}$ emissions resulting from electricity production in Spain, and the manufacture of $P V$ components, as obtained from references $[16,17]$. For each type of 
winery, we calculated the $\mathrm{CO}_{2}$ emitted into the atmosphere, based on the energy provided by the grid and the renewable energy source, (see Table 5).

Table 5. Emission factor of equivalent $\mathrm{CO}_{2}$.

\begin{tabular}{cc}
\hline Energy Sources & $\mathbf{C O}_{\text {2-eq }}(\mathbf{g} / \mathbf{k W h})$ \\
\hline Grid electricity & 330 \\
$P V$ system & 37 \\
\hline
\end{tabular}

\section{Results and Discussion}

HOMER studied all configurations that were technically viable and then ordered them in terms of their Net Present Cost (NPC). Table 6 shows the results of the most cost-effective configurations of wineries powered by a grid-connected photovoltaic system. This table specifies the electrical power that should be contracted from the electricity company, depending on the size of the winery. The other columns in the table show the optimal quantity of photovoltaic power required so that the sum of electricity, exploitation, and maintenance costs are the lowest possible.

Table 6. Power.

\begin{tabular}{ccccc}
\hline \multirow{2}{*}{ Unit: kW } & \multirow{2}{*}{ Grid } & \multicolumn{3}{c}{ Grid-Connected $P \boldsymbol{V}$} \\
\cline { 3 - 5 } & & Self-Consumption & Monthly Net Metering & Annual Net Metering \\
\hline Small & 199 & 26 & 57 & 87 \\
Medium & 360 & 14 & 61 & 100 \\
Large & 568 & 0 & 32 & 32 \\
\hline
\end{tabular}

The photovoltaic power that must be installed to reduce these costs depends on the billing policy of the electricity company for the energy thus generated (i.e., self-consumption and/or net metering) as well as the time period of the billing. According to Spanish regulations, $100 \mathrm{~kW}$ is the maximum power of a grid-connected renewable energy installation. Because of this limit, medium-size wineries have an optimal installed photovoltaic power of $100 \mathrm{~kW}$ for the annual net metering. If this limit did not exist, the installed photovoltaic power would be greater. From an economic viewpoint, this solution would be more profitable.

In regard to self-consumption, the winery prioritizes the consumption of electricity generated by the photovoltaic system. It only uses the electrical energy from the grid that the $P V$ installation is unable to supply. Moreover from December to July, when there is a low demand, the excess energy is fed into the grid. It is then sold to the electricity company at the price agreed on by the winery and the company (see Figure 6). Equation (6) can be used to obtain the net energy cost for the entire billing period in the self-consumption mode.

$$
C_{\text {Self-consumption }}=I E_{S C} \times C_{G \text { rid }}-E E_{S C} \times C_{P V}
$$

where $I E_{S C}(\mathrm{kWh})$ is the electrical energy taken from the grid during the billing period: $C_{\text {Grid }}(€ / \mathrm{kWh})$ is the price paid by the winery for the energy consumed from the grid; $E E_{s c}(\mathrm{kWh})$ is the excess electrical energy (produced by the $P V$ system) that is fed to the grid during the billing period; and $C_{P V}$ $(€ / \mathrm{kWh})$ is the price paid by the electricity company for this energy from a renewable source.

Rather surprisingly, the results in Table 6 indicate that for wineries (of any size) in the self-consumption mode, the best option is not to install the $100 \mathrm{~kW}$ of photovoltaic power permitted by Spanish law. This is because the installation and maintenance costs of such a system would be higher than the profits obtained during its useful life. As can be observed, the most profitable solution would be to install $26 \mathrm{~kW}, 14 \mathrm{~kW}$, and $0 \mathrm{~kW}$ of photovoltaic power for small, medium, and large wineries, respectively. 
In the net metering mode, the winery obtains electricity directly from the grid, whereas all of the electrical energy generated by the photovoltaic system is fed into the grid. In this case, there are two types of net metering, depending on whether the metering of the difference between the electricity fed into the grid and consumed from the grid is billed annually or monthly. This difference in billing has significant impact on the results (see Table 6). At present, these different modes of net metering are not available in Spain. Nevertheless, since they do exist in other wine-producing countries, the results would be applicable to those cases.

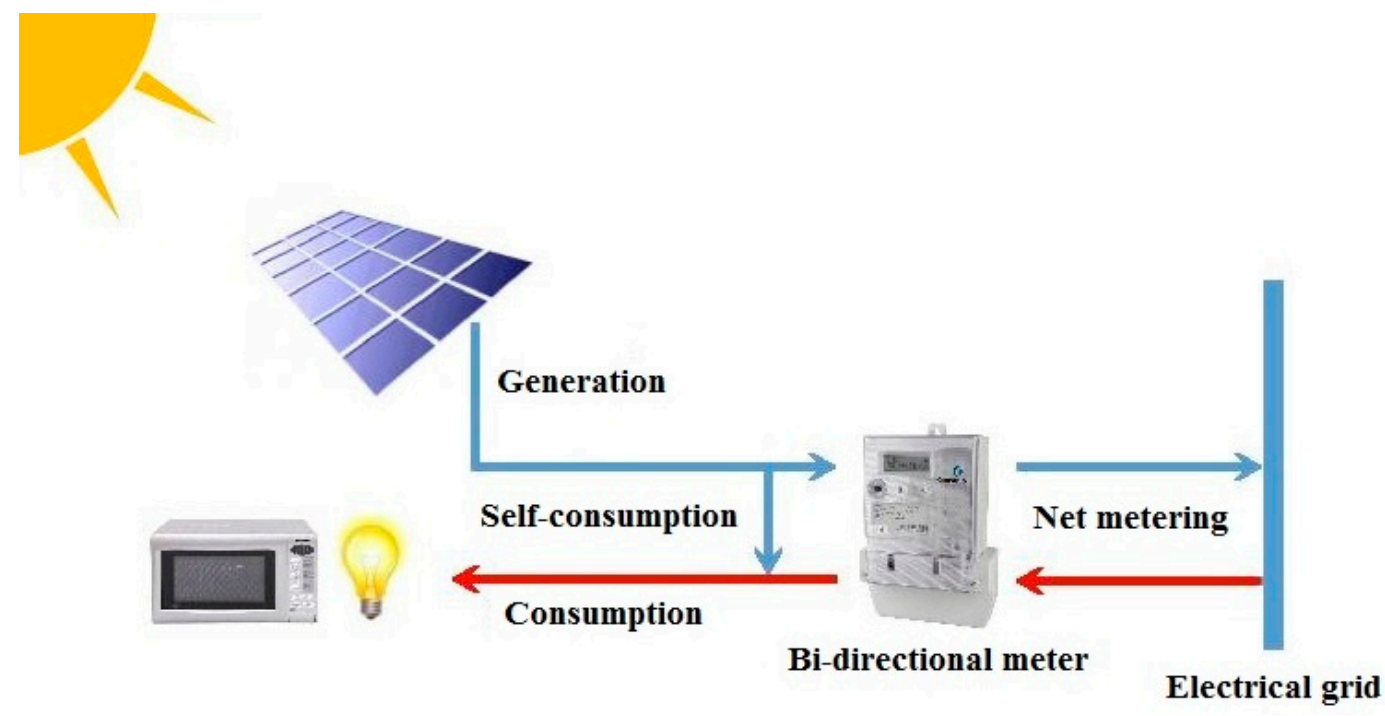

Figure 6. Scheme of a grid-connected $P V$ system and of the differences between self-consumption and net metering [18].

The energy costs in net metering with monthly or annual billing periods can be calculated with Equation (7):

$$
C_{\text {Net Metering }}=\left\{\begin{array}{c}
\left(I E_{N M}-E E_{N M}\right) \times C_{G r i d} \text { if }\left(I E_{N M}-E E_{N M}\right) \geq 0 \\
\left(I E_{N M}-E E_{N M}\right) \times C_{P V} \text { if }\left(I E_{N M}-E E_{N M}\right)<0
\end{array}\right.
$$

where $I E_{N M}(\mathrm{kWh})$ is the total electrical energy consumed by the winery, and thus obtained from the grid during the billing period; and $E E_{N M}(\mathrm{kWh})$ is the total electrical energy produced by the $P V$ system that is fed into the grid during the billing period. The following sections present the economic and environmental data that quantitatively demonstrate the results in Table 6.

\subsection{Economical Impact}

To determine the viability of each optimization solution, based on its total cost, HOMER provided the Net Present Cost (NPC) value for the photovoltaic system with a useful life of 25 years. Table 7 shows the NPC values for small, medium, and large wineries as well as for the three billing modes. As can be observed, an electricity supply exclusively from the grid is clearly more expensive than an electricity supply from the grid supplemented with electricity from photovoltaic installations, despite the costs generated. Moreover, of the solutions that include a photovoltaic system, the least expensive billing mode is the annual net metering as opposed to self-consumption. 
Table 7. Net Present Cost (NPC).

\begin{tabular}{ccccc}
\hline \multirow{2}{*}{ Unit: $\times \mathbf{1 0}^{\mathbf{3}} \boldsymbol{\epsilon}$} & \multirow{2}{*}{ Grid } & \multicolumn{3}{c}{ Grid-Connected $\boldsymbol{P V}$} \\
\cline { 3 - 5 } & & Self-Consumption & Monthly Net Metering & Annual Net Metering \\
\hline Small & 661.3 & 652.6 & 620.6 & 584.0 \\
Medium & 1044.3 & 1042.8 & 1018.2 & 1009.6 \\
Large & 1445.1 & 1445.1 & 1439.4 & 1439.4 \\
\hline
\end{tabular}

Table 8 shows the cost of electrical energy when electricity is solely obtained from the grid as well as for those cases where there is grid-connected photovoltaic power. Once again, the solutions that contemplate a photovoltaic installation as a supplement for the electricity consumed by the winery are more cost-effective (i.e., lower kWh price) than the conventional model. As in the NPC, the lowest $\mathrm{kWh}$ price was achieved with annual net metering whereas the highest $\mathrm{kWh}$ was obtained for self-consumption.

Table 8. Cost of Energy (COE).

\begin{tabular}{ccccc}
\hline \multirow{2}{*}{ Unit: $\boldsymbol{€} / \mathbf{k W h}$} & \multirow{2}{*}{ Grid } & \multicolumn{3}{c}{ Grid-Connected $\boldsymbol{P V}$} \\
\cline { 3 - 5 } & & Self-Consumption & Monthly Net Metering & Annual Net Metering \\
\hline Small & 0.183 & 0.168 & 0.143 & 0.116 \\
Medium & 0.160 & 0.157 & 0.142 & 0.130 \\
Large & 0.141 & 0.141 & 0.136 & 0.136 \\
\hline
\end{tabular}

The results in Table 8 were calculated based on the rates given in Section 4.4, which are the averages of all the rates available for each winery type.

\subsection{Environmental Impact and Sustainability}

The environmental impact and the energy sustainability of the most cost-effective solutions for all of the wineries is addressed in this section. The data that indicate the sustainability of the solution provided are the following: (i) percentage of renewable energy consumed by the winery; (ii) direct or indirect $\mathrm{CO}_{2}$ emissions.

Table 9 shows the electrical energy produced by the $P V$ installations as compared to the total electricity consumed by the wineries. The ratio of the energy supplied by renewable sources as a function of the total energy demand would have been higher if we had considered the thermal energy supplied by biomass boilers. As can be observed in Table 9, the percentage of renewable energy goes from $0 \%$ to $57 \%$ for the technically viable and most cost-effective solutions.

Table 9. Renewable energy.

\begin{tabular}{ccccc}
\hline \multirow{2}{*}{ Unit: $\%$} & \multirow{2}{*}{ Grid } & \multicolumn{3}{c}{ Grid-Connected $\boldsymbol{P V}$} \\
\cline { 3 - 5 } & & Self-Consumption & Monthly Net Metering & Annual Net Metering \\
\hline Small & 0 & 22 & 43 & 57 \\
Medium & 0 & 7 & 28 & 42 \\
Large & 0 & 0 & 10 & 10 \\
\hline
\end{tabular}

Table 10 shows the annual electricity consumption of each type of winery, as based on its corresponding rate and billing policy. Also specified is how much of this consumption comes from the grid, and how much comes from renewable energy. 
Table 10. Annual electricity consumption.

\begin{tabular}{ccccccc}
\hline \multirow{2}{*}{ Unit: kWh/year } & \multicolumn{2}{c}{ Self-Consumption } & \multicolumn{2}{c}{ Monthly Net Metering } & \multicolumn{2}{c}{ Annual Net Metering } \\
\cline { 2 - 7 } & Grid & $\boldsymbol{P V}$ & Grid & $\boldsymbol{P V}$ & Grid & $\boldsymbol{P V}$ \\
\hline Small & 125,291 & 38,161 & 99,396 & 83,662 & 83,562 & 127,694 \\
Medium & 264,514 & 20,928 & 212,349 & 89,533 & 181,252 & 146,775 \\
Large & 450,109 & 0 & 339,340 & 46,968 & 339,340 & 46,968 \\
\hline
\end{tabular}

Moreover, as reflected in Table 11, the average $\mathrm{CO}_{2}$ emissions were calculated for the three types of winery (those only connected to the grid and those using grid-connected $P V$ systems), based on the data in Table 5.

Table 11. Equivalent $\mathrm{CO}_{2}$ emissions.

\begin{tabular}{cc}
\hline Size & Tn/year \\
\hline Small & 52.2 \\
Medium & 94.2 \\
Large & 148.5 \\
\hline
\end{tabular}

The $\mathrm{CO}_{2}$ emissions reached a total of $38.1 \%$ in small wineries, $30.8 \%$ in medium wineries, and $23.4 \%$ in large wineries (see Table 12). The bar chart in Figure 7 shows the emission levels of the three types of winery.

Table 12. Equivalent $\mathrm{CO}_{2}$ emissions (grid-connected $P V$ system).

\begin{tabular}{cccc}
\hline Unit: Tn/year & Self-Consumption & Monthly Net Metering & Annual Net Metering \\
\hline Small & 42.8 & 35.9 & 32.3 \\
Medium & 88.1 & 73.4 & 65.2 \\
Large & 148.5 & 113.7 & 113.7 \\
\hline
\end{tabular}

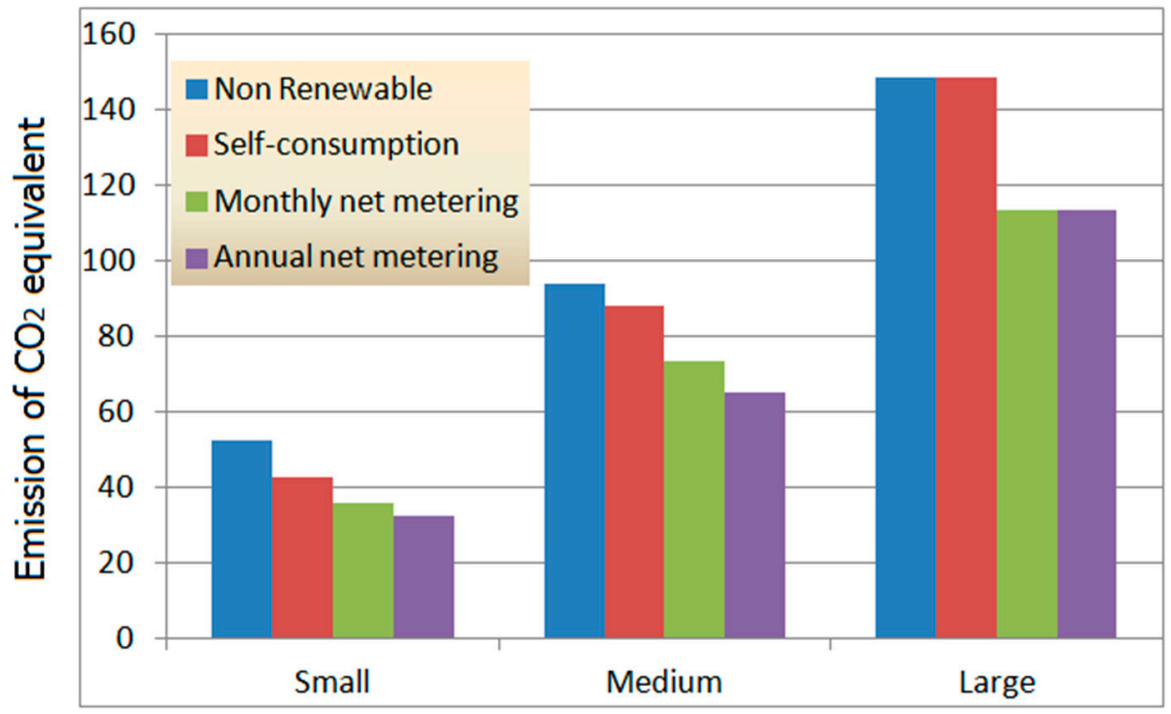

Figure 7. Equivalent $\mathrm{CO}_{2}$ emissions.

\subsection{Impact on the Market}

As explained in Section 1, one of the goals of this study was to lower the price of wine. Table 13 shows the average price of the energy required to produce a hectoliter of wine in 2007-2009 (FUTS 2015). 
Table 13. Price of the energy required to produce a hectoliter of winery in 2007-2009 [8].

\begin{tabular}{cc}
\hline Size & $\boldsymbol{\epsilon} / \mathbf{h L}$ \\
\hline Small & 2.31 \\
Medium & 1.26 \\
Large & 0.43 \\
\hline
\end{tabular}

Table 14 shows the real price of wine, as obtained for the three types of winery and the four types of electricity consumption studied. As can be observed, in small wineries, the price per hectoliter of wine increased $29 \%$ between 2007 and 2014. In medium-size wineries the rise in price was $28 \%$ during the same period, and finally, in large wineries it increased 23\% (based on Spanish energy prices).

Table 14. Energy price per hl of wine produced (year 2014).

\begin{tabular}{ccccc}
\hline \multirow{2}{*}{ Unit: $\boldsymbol{\ell} / \mathbf{h L}$} & \multirow{2}{*}{ Grid } & \multicolumn{3}{c}{ Grid-Connected $\boldsymbol{P V}$} \\
\cline { 3 - 5 } & & Self-Consumption & Monthly Net Metering & Annual Net Metering \\
\hline Small & 2.98 & 2.74 & 2.33 & 1.89 \\
Medium & 1.61 & 1.58 & 1.43 & 1.31 \\
Large & 0.53 & 0.53 & 0.51 & 0.51 \\
\hline
\end{tabular}

When the optimal configuration is applied, the price of the energy consumed per hectoliter of wine experiences a reduction of $36 \%$ in small wineries, $19 \%$ in medium-size wineries and $4 \%$ in large wineries, depending on whether the billing is monthly or annually.

Precisely because of the outdated technology in most wineries, there are huge savings in the energy price per hectoliter that come with the installation of renewable energy systems. It is worth highlighting that large wineries have a smaller optimization margin because of the competitive rates achieved. Large wineries thus have lower benefits (20.67\% less than small wineries and $9.34 \%$ less than medium-size wineries).

\section{Conclusions}

This research assessed the environmental, economic, and technical viability of using grid-connected photovoltaic installations to power the operation of wineries in Spain. As part of this study, the wineries were classified as small, medium, or large, depending on their volume of wine production. Of the thermally viable solutions, the most cost-effective one was calculated. For the purposes of this study, the HOMER computer application was used. The installation, maintenance, and eventual replacement of the photovoltaic system after a useful life of 25 years was also taken into account.

Three billing and metering policies were included. We compared our calculations with conventional electricity rates, whose price has soared in recent years. Our results confirmed that the configurations proposed in our study could substantially reduce power costs in the winemaking industry, one of the most important in Spain. The following conclusions can be derived from this research study.

Firstly, from an economic perspective, the NPC of the installation was the optimization criterion. The costs of the system were those related to installation, maintenance, and electricity consumption during its useful life. Small wineries saved $11.7 \%$ whereas large wineries saved $0.4 \%$. In all likelihood, these percentages will increase in the future because the price of electricity will progressively rise, and technology will become more efficient. In regard to the price per KWh paid by the winery, we obtained savings of $37.2 \%$ (from $0.183 € / \mathrm{kWh}$ without renewables to $0.116 € / \mathrm{kWh}$ with renewables) in small wineries and up to $9 \%$ in large wineries (from $0.141 € / \mathrm{kWh}$ without renewable to $0.136 € / \mathrm{kWh}$ with renewables), depending on the billing and metering policy.

Secondly, from an environmental perspective, the quantity of renewable energy depends on the size of the winery as well as the billing and the metering policy. The amount of renewable energy 
ranged from $0 \%$ to $57 \%$. These percentages would be higher if biomass were used to feed the thermal demand, or if the conventional energy sources used in the construction of the $P V$ system were not considered. On the other hand, $\mathrm{CO}_{2}$ emissions experienced a reduction that ranged from $23.4 \%$ to $38.1 \%$. This is in consonance with the EU objective of reducing $\mathrm{CO}_{2}$ emissions by $20 \%$ in different economic sectors [19].

Finally, the use of renewable energy had a positive impact on the price of wine production, which decreased more than $36 \%$ in the case of small wineries, and more than $4 \%$ in the case of large wineries. It is our expectation that these research results will help wineries design an optimal $P V$ support system that will make wine production more cost-effective.

Author Contributions: Daniel Gómez-Lorente was primarily responsible for the compilation of information and the development of the simulation configuration; Ovidio Rabaza was responsible for the technical supervision of the article, because of his knowledge of the agri-food sector and winery design and management; Fernando Aznar-Dols was responsible for the data processing; María José Mercado-Vargas was the general coordinator of this research.

Conflicts of Interest: The authors declare no conflict of interest.

\section{References}

1. Soshinskaya, M.; Crijns-Graus, W.H.J.; Van der Meer, J.; Guerrero, J.M. Application of a microgrid with renewables for a water treatment plant. Appl. Energy 2014, 134, 20-34. [CrossRef]

2. Chel, A.; Kaushik, G. Renewable energy for sustainable agriculture. Agron. Sustain. Dev. 2011, 31, 91-118. [CrossRef]

3. Mekhilef, S.; Faramarzi, S.Z.; Saidur, R.; Salam, Z. The application of solar technologies for sustainable development of agricultural sector. Renew. Sustain. Energy Rev. 2013, 18, 583-594. [CrossRef]

4. Squatrito, R.; Sgroi, F.; Tudisca, S.; Trapani, A.M.D.; Testa, R. Post Feed-in Scheme Photovoltaic System Feasibility Evaluation in Italy: Sicilian Case Studies. Energies 2014, 7, 7147-7165. [CrossRef]

5. Sgroi, F.; Tudisca, S.; Di Trapani, A.M.; Testa, R.; Squatrito, R. Efficacy and efficiency of Italian energy policy: The case of PV systems in greenhouse farms. Energies 2014, 7, 3985-4001. [CrossRef]

6. Rabaza, O.; Contreras-Montes, J.; García-Ruiz, M.J.; Delgado-Ramos, F.; Gómez-Lorente, D. Techno-economic performance evaluation for olive mills powered by grid-connected photovoltaic systems. Energies 2015, 8, 11939-11954. [CrossRef]

7. Revista Oficial Del Medio Ambiente. Available online: https://mirevistadigital.files.wordpress.com/2013/ 01/analisis-sector-del-vino-en-espac3b1a.pdf (accessed on 30 September 2016).

8. FUTS. Manual de Ahorro y Eficiencia Energética del Sector. Bodegas. Available online: http://www.agroalimentarias.coop/ficheros/doc/03200.pdf (accessed on 21 September 2015).

9. Wikipedia Commons, the Free Media Repository. Available online: https://en.wikipedia.org/wiki/Climate_ of_Spain (accessed on 22 April 2015).

10. Wikipedia Commons, the Free Media Repository. Available online: https://commons.wikimedia.org/wiki/ File:Europe_location_Spain.PNG (accessed on 21 April 2015).

11. Fazelpour, F.; Soltani, N.; Rosen, M.A. Feasibility of satisfying electrical energy needs with hybrid systems for a medium-size hotel on Kish Island, Iran. Energy 2014, 73, 856-865. [CrossRef]

12. Dalton, G.J.; Lockington, D.A.; Baldock, T.E. Feasibility analysis of renewable energy supply options for a grid-connected large hotel. Renew. Energy 2009, 34, 955-964. [CrossRef]

13. Euro Area Statistics. Available online: https://www.euro-area-statistics.org/index?cr=eur\&lg=en (accessed on 15 July 2015).

14. Ramos-Paja, C.A.; Saavedra-Montes, A.J.; Trejos, L.A. Estimating the produced power by photovoltaic installations in shaded environments. Dyna 2015, 82, 37-43. [CrossRef]

15. NREL. Distributed Generation Renewable Energy Estimate of Costs. Available online: http:/ /www.nrel. gov/analysis/tech_lcoe_re_cost_est.html (accessed on 15 July 2015).

16. IDAE. Factores de Conversión Energía Final-Energía Primaria y Factores de Emisión de $\mathrm{CO}_{2}, 2011$. Available online: http://www.idae.es/uploads/documentos/documentos_Factores_Conversion_Energia_ y_CO2_2011_0a9cb734.pdf (accessed on 21 September 2015). 
17. Fthenakis, V.; Alsema, E. Photovoltaics energy payback times, greenhouse gas emissions and external costs: 2004-early 2005 status. Prog. Photovolt. Res. Appl. 2006, 14, 275-280. [CrossRef]

18. Wikipedia Commons, the Free Media Repository. Available online: http://commons.wikimedia.org/wiki/ File:Esquema-autoconsumo.svg (accessed on 20 July 2015).

19. European Union Council. Energy and Climate Change. Elements of the Final Compromise. EU Document $\mathrm{N}^{\circ}$ 17215/08. Available online: http://www.consilium.europa.eu/uedocs/cms_data/docs/pressdata/en/ ec/104672.pdf (accessed on 4 September 2015). 